\title{
Expression of RUNX3 Gene, Methylation Status and Clinicopathological Significance in Breast Cancer and Breast Cancer Cell Lines
}

\author{
Ying Jiang $^{\mathrm{a}}$ Dandan Tong $^{\mathrm{b}}$ Ge Lou $^{\mathrm{a}}$ Ying Zhang $^{\mathrm{a}}$ Jingshu Geng ${ }^{\mathrm{c}}$ \\ ${ }^{a}$ Department of Pathology, Second Affiliated Hospital of Harbin Medical University, ${ }^{b}$ Department of Pathology, \\ Basic Medical College, Harbin Medical University, and ${ }^{\mathrm{C}}$ Department of Pathology, Third Affiliated Hospital of \\ Harbin Medical University, Harbin, China
}

\section{Key Words}

Breast cancer $\cdot$ Methylation $\cdot$ RUNX3 gene $\cdot$ Prognosis

\begin{abstract}
Background: Runt-related transcription factor 3 (RUNX3) is a novel tumor suppressor gene that is frequently silenced by promoter hypermethylation in gastric cancer. In this study, we aimed to analyze the methylation status of the RUNX3 promoter in breast cancer and to evaluate the relationship between RUNX3 expression and breast carcinogenesis and prognosis. Methods: RT-PCR and Western blot were applied on 5 breast cancer cell lines, the human normal breast cell line Hs578Bst and 30 pairs of breast cancer and their matching normal breast tissues to detect mRNA and protein expression of the RUNX3 gene. Methylation-specific PCR was employed to detect the methylation status of the RUNX3 promoter. Immunohistochemical study was performed to analyze RUNX3 protein expression in 88 breast cancer tissues and 40 breast fibroadenomas. Results: The expression of RUNX3 mRNA and protein were negative in 3 breast cancer cell lines (T47D, MCF7 and SKBR3) as analyzed by RT-PCR and Western blotting. Hypermethylation of the RUNX3 promotor was identified in the T47D and MCF7 cell lines, but was not detected in SKBR3. Western blot analysis showed that the RUNX3 protein of $44 \mathrm{kDa}$ was detected in 15 of 30 (50\%) breast cancers. However, RUNX3 protein was detected in all normal breast tissues. Methylation was detected in 13 of the
\end{abstract}

15 tissues (86.67\%) that did not express RUNX3 protein, but was never detected in any surrounding normal tissues. Immunohistochemistry results revealed that the positive rate of RUNX3 protein expression in breast cancer (35.23\%) was much lower than that in breast fibroadenoma (85\%). RUNX3 expression was correlated with tumor infiltration, clinical stage, lymph node metastasis and the expression of estrogen and progesterone receptor ( $p<0.05$ ), but was not related to age, tumor types and pathological grade ( $p>0.05)$. The survival rate of the patients with RUNX3-positive expression was higher than that with RUNX3-negative expression $(p<0.05)$. Conclusions: The expression of RUNX3 gene is decreased in breast cancer. The RUNX3 gene may play an important role in the carcinogenesis of breast cancer. The mechanism of its inactivation may be hypermethylation of the promoter. With the increased progression of breast cancer, the expression of RUNX3 protein tends to decrease. The expression of RUNX3 protein has a definite value in judging prognosis in breast cancer.

Copyright $\odot 2008$ S. Karger AG, Basel

\section{Introduction}

Breast cancer is the most common cancer in women both in China and in many other countries. With advances in diagnostic techniques and treatment methods, the prognosis of breast cancer has improved. However, in

\section{KARGER}

Fax +4161306 1234 E-Mail karger@karger.ch www.karger.com
(C) 2008 S. Karger AG, Basel

$1015-2008 / 08 / 0754-0244 \$ 24.50 / 0$

Accessible online at:

www.karger.com/pat
Prof. Geng Jingshu

Department of Pathology

Third Affiliated Hospital of Harbin Medical University, Haping Road 150

Nangang District, Harbin, Heilongjiang, 150086 (PR China)

Tel./Fax +86 4518629 8232, E-Mail jeangeng2004@yahoo.com.cn 
China the incidence of breast cancer is increasing. It is necessary to identify the genetic changes in the carcinogenesis and progression of breast cancer.

The Runt family of transcription factors consists of 3 members, RUNX1 (PEBP2aB/CBFA2/AML1), RUNX2 (PEBP2aA/CBFA1/AML3) and RUNX3 (PEBP2aC/ CBFA3/AML2) [1]. All 3 RUNX family members play important roles in normal developmental processes and in carcinogenesis [2-4]. RUNX3 is an integral component of a signaling cascade mediated by transforming growth factor- $\beta$ (TGF- $\beta$ ) [5]. Li et al. [6] reported that the RUNX3 protein has essential functions in both cell proliferation and differentiation in gastric epithelium. The gastric epithelium of RUNX3 knockout mice demonstrated hyperplasia and a reduced rate of apoptosis, accompanied by a reduced sensitivity to TGF- $\beta$. Interestingly, $1 \mathrm{p} 36$, where RUNX3 maps according to Bae et al. [7], is a region commonly deleted in a wide variety of human carcinomas, including breast cancer [8]. Therefore, it is of great interest to examine whether inactivation of RUNX3 occurs in breast cancer as well.

In the present study, 5 breast cancer cell lines and 30 paired breast cancer and normal tissues were tested for the methylation status of the RUNX3 gene promoter. We also examined the expression of RUNX3 protein and mRNA both in the breast cancer cell line and breast cancer tissues. In addition, we analyzed the relationship between RUNX3 expression and clinicopathological features in breast cancer.

\section{Materials and Methods}

\section{Cell Lines and Culture Conditions}

The human breast cancer cell lines (Bcap37, BT549, SKBR3, MCF7 and T47D) and the human normal breast cell line Hs578Bst were obtained from Cell Bank, Chinese Academy of Sciences, Shanghai, China. All cell lines were maintained at $37^{\circ} \mathrm{C}$ in a humidified atmosphere of 5\% $\mathrm{CO}_{2}$ and 95\% air, in RPMI 1640 (GibcoBRL, Tokyo, Japan) supplemented with $10 \%$ fetal bovine serum.

\section{Human Tissue Specimens and Patient Information}

We obtained frozen tissue samples of 30 pairs of breast cancer and their matching normal breast tissues from the Second Affiliated Hospital of Harbin Medical University. Eighty-eight formalin-fixed, paraffin wax-embedded tissues of human breast cancer resected in 2000-2001 were retrieved from the Pathology Department of the Second Affiliated Hospital of Harbin Medical University. Paraffin blocks were sectioned in $4-\mu \mathrm{m}$ slices and stained with hematoxylin and eosin. We obtained 40 breast fibroadenoma tissues as benign tumor controls. All patient information was obtained. The tumors were classified by 2 experienced pathologists according to the WHO standard. The patients had a well-
Table 1. Relationship between RUNX3 expression and clinicopathological data in 88 breast cancers

\begin{tabular}{|c|c|c|c|c|}
\hline \multirow[t]{2}{*}{ Variables } & \multirow{2}{*}{$\begin{array}{l}\text { Total } \\
(\mathrm{n}=88)\end{array}$} & \multicolumn{2}{|c|}{ RUNX3 expression } & \multirow[t]{2}{*}{$\mathrm{p}$} \\
\hline & & positive & negative & \\
\hline \multicolumn{5}{|l|}{ Age } \\
\hline $27-52$ years & 45 & 17 & 28 & \multirow[t]{2}{*}{$>0.05$} \\
\hline $53-83$ years & 43 & 14 & 29 & \\
\hline \multicolumn{5}{|l|}{ Tumor types } \\
\hline Ductal carcinoma & 57 & 18 & 39 & \multirow[t]{2}{*}{$>0.05$} \\
\hline Lobular carcinoma & 31 & 13 & 18 & \\
\hline \multicolumn{5}{|l|}{ Tumor infiltrating } \\
\hline Carcinoma in situ & 18 & 11 & 7 & \multirow[t]{2}{*}{$<0.05$} \\
\hline Invasive carcinoma & 70 & 20 & 50 & \\
\hline \multicolumn{5}{|l|}{ Carcinoma in situ } \\
\hline DCIS & 11 & 8 & 3 & \multirow[t]{2}{*}{$>0.05$} \\
\hline LCIS & 7 & 3 & 4 & \\
\hline \multicolumn{5}{|l|}{ Invasive carcinoma } \\
\hline IDC & 46 & 14 & 32 & \multirow[t]{2}{*}{$>0.05$} \\
\hline ILC & 24 & 6 & 18 & \\
\hline \multicolumn{5}{|c|}{ Histological grade of IDC } \\
\hline I & 14 & 5 & 9 & \multirow[t]{3}{*}{$>0.05$} \\
\hline II & 20 & 6 & 14 & \\
\hline III & 12 & 3 & 9 & \\
\hline \multicolumn{5}{|l|}{ Lymph node metastasis } \\
\hline Positive & 41 & 8 & 33 & \multirow[t]{2}{*}{$<0.05$} \\
\hline Negative & 47 & 23 & 24 & \\
\hline \multicolumn{5}{|l|}{ Clinical stage } \\
\hline I-II & 52 & 24 & 28 & \multirow[t]{2}{*}{$<0.05$} \\
\hline III-IV & 36 & 7 & 29 & \\
\hline \multicolumn{5}{|l|}{ ER expression } \\
\hline++ & 40 & 21 & 19 & \multirow[t]{2}{*}{$<0.05$} \\
\hline- or + & 48 & 10 & 38 & \\
\hline \multicolumn{5}{|l|}{ PR expression } \\
\hline++ & 42 & 22 & 20 & \multirow[t]{2}{*}{$<0.05$} \\
\hline- or + & 46 & 9 & 37 & \\
\hline
\end{tabular}

DCIS = Ductal carcinoma in situ; LCIS = lobular carcinoma in situ; IDC = invasive ductal carcinoma; ILC = invasive lobular carcinoma.

documented clinical history and follow-up information. None of them underwent preoperative chemotherapy and/or radiotherapy. Details of the patients' characteristics are provided in table 1.

\section{RT-PCR Assay for RUNX3}

An RT-PCR assay was used to examine RUNX3 mRNA expression. Total RNA was extracted from samples with Trizol reagent (Invitrogen, Carlsbad, Calif., USA) and cDNA was synthesized from total RNA with oligo-dT primer (Reverse Transcription System; Promega, Madison, Wisc., USA) following the manufacturer's instructions. Primer sequences for RUNX3 amplification were: forward, 5'-TCATGAAGAACCAGGTGG-3'; reverse, 5'-AGGTAGGTATGGTGGAAGC-3' (GenBank accession No. NM_004350.1). The PCR reactions were performed in a thermal cycler (GeneAmp RCR System 9600; Applied Biosystems, 
Foster City, Calif., USA). The amplification program for the RUNX3 transcript was $30 \mathrm{~s}$ at $94^{\circ} \mathrm{C}, 30 \mathrm{~s}$ at $56^{\circ} \mathrm{C}$ and $50 \mathrm{~s}$ at $72^{\circ} \mathrm{C}$ for 30 cycles. The housekeeping gene $\beta$-actin was used as an internal control to confirm the success of the RT reaction. Primer sequences for $\beta$-actin amplification were: forward, $5^{\prime}$-ACCGCGAGAAGATGACCCAG-3'; reverse, 5'-TTAATGTCACGCACGATTTCCC-3'. These primer sequences were identical to the endogenous human target genes as confirmed by a BLAST search. PCR products were analyzed on $2 \%$ agarose gels.

\section{DNA Extraction and Methylation-Specific PCR}

Genomic DNA was obtained from cell lines and primary cancers by digestion with proteinase K (Sigma, St. Louis, Mo., USA), followed by phenol/chloroform (1:1) extraction [9]. DNA methylation patterns in the CpG island of RUNX3 were determined by the methylation-specific PCR (MSP) method as reported by Herman et al. [10]. Briefly, $4 \mu$ g genomic DNA was denatured by $\mathrm{NaOH}$ and modified by sodium bisulfite. The modified DNA was purified using a Wizard DNA purification kit (Promega), treated with $\mathrm{NaOH}$ to desulfonate, precipitated with ethanol and resuspended in water. PCR amplification was performed with bisulfite-treated DNA as a template using specific primer sequences for the methylated and unmethylated forms of the genes. Primer sequences of RUNX3 for methylated reaction were as follows: forward, $5^{\prime}$-ATAATAGCGGTCGTTAGGGCGTCG-3'; reverse, 5'-GCTTCTACTTTCCCACTTCTCACA-3'. Those for the unmethylated reaction were: forward, 5'-ATAATAGTGGTTGTTAGGGTGTTG-3'; reverse, 5'-ACTTCTACTTTCCCACTTCTCACA-3'.

Step-down PCR reactions were performed in a $20-\mu l$ reaction volume containing $10 \times$ buffer (including $\mathrm{Mg}^{2+}$ ) $2 \mu \mathrm{l}$, dNTP $2 \mu \mathrm{l}$, $0.5 \mu \mathrm{l}$ of each PCR primer, $0.5 \mu \mathrm{l}$ of AmpliTaq polymerase, $2 \mu \mathrm{l}$ of bisulfite-modified DNA and $12.5 \mu$ l diethyl pyrocarbonatetreated water. Reactions were hot started at $95^{\circ} \mathrm{C}$ for $2 \mathrm{~min}$. This was followed by 35 cycles at $95^{\circ} \mathrm{C}$ for $30 \mathrm{~s}, 55^{\circ} \mathrm{C}$ for $30 \mathrm{~s}$ and $72^{\circ} \mathrm{C}$ for $45 \mathrm{~s}$, followed by a 7 -min extension at $72^{\circ} \mathrm{C}$. The amplification products were separated on a $2 \%$ agarose gel and visualized by UV transillumination.

DNA from peripheral blood lymphocytes $(n=10)$ from healthy subjects was used as negative control. DNA from lymphocytes of a healthy volunteer treated with Sss1 methyltransferase (Sigma) and then subjected to bisulfate treatment was used as a positive control for methylated alleles. Results were confirmed by repeating bisulfite treatment and MSP for all samples.

\section{Western Blot Analysis}

Whole-cell lysates were prepared from tissue specimens or cell culture. Samples were boiled in SDS sample buffer for $5 \mathrm{~min}$ before running on a $10-20 \%$ SDS polyacrylamide gel. After blocking the blot in 3\% BSA for $2 \mathrm{~h}$ at room temperature, the membrane was blotted with anti- $\beta$-actin monoclonal antibody (1:1,000; Sigma) and anti-RUNX3 polyclonal antibody (1:500; Activemotif, Carlsbad, Calif., USA). Horseradish peroxidase-conjugated secondary antibodies were incubated with the blot at 1:1,000 dilution for $1 \mathrm{~h}$ at room temperature. After extensive washing, specific bands were detected using an enhanced chemiluminescence system (ECL Detection System; Amersham Biosciences, Uppsala, Sweden).

\section{Immunohistochemistry}

Sections ( $4 \mu \mathrm{m}$ thick) of formalin-fixed, paraffin-embedded tumor specimens were prepared and processed as previously de- scribed [11]. RUNX3 protein expression was detected with a rabbit polyclonal antibody against human RUNX3 (Activemotif). The antibody was in a 1:150 dilution. A positive reaction was indicated by a reddish brown precipitate in the nucleus. RUNX3 immunoreactivity was classified into 2 groups: negative expression, when the positive cells were less than $10 \%$, and positive expression, when the positive cells were $10 \%$ or more. Estrogen receptor (ER) and progesterone receptor (PR) protein expression were detected with a mouse monoclonal antibody against human. Depending on the percentage of positive cells and staining intensity, ER and PR expression were classified into 4 groups: negative (less than $10 \%$ positive cells), $+(10-50 \%$ positive cells), $++(51-$ $75 \%$ positive cells) and +++ ( $76 \%$ or more positive cells). Two independent investigators scored the sections without the knowledge of patient outcome (double blinded). An average value of 2 independent scores is given in the present study.

Statistics

The $\chi^{2}$ test was performed to determine the significance of the difference between the covariates. Survival durations were calculated with the Kaplan-Meier method. The log-rank test was used to compare the cumulative survival durations in the patient groups. The Cox proportional hazards model was used to compute univariate and multivariate hazards ratios for the study variables. The patients' level of RUNX3 expression, lymph node status, ER and PR status and histopathological grade were included in the model. $\mathrm{p}<0.05$ was defined as being statistically significant. The SPSS software (version 11.05; SPSS Inc., Chicago, Ill., USA) was used for the analyses.

\section{Results}

\section{The Expression of RUNX3 $m R N A$ and Protein in Breast Cancer Cell Lines}

We examined the expression of RUNX3 mRNA in breast cancer cell lines by RT-PCR. As shown in figure la, the expression of RUNX3 mRNA was undetectable in the T47D, MCF7 and SKBR3 cell lines, while control reaction products $(\beta$-actin) were detected in all cell lines. Next, Western blot analysis was done on the same panel of breast cells to determine whether alterations in mRNA expression of RUNX3 were accompanied by corresponding changes at the protein level as well. The expression of RUNX3 protein was detected in Bcap37, BT549 and the human normal breast cell line Hs578Bst (fig. 1b). The level of RUNX3 mRNA expression correlated with the level of RUNX3 protein. Overall, of the 5 cancer cell lines tested, 3 (60\%) did not express RUNX3 at mRNA and protein levels.

\section{RUNX3 Expression and Localization in Breast Cancer Tissues}

RUNX3 expression was evaluated in 88 human breast cancers and 40 breast fibroadenomas by immunohisto- 
chemistry. Positive expression of RUNX3 protein was found in $31(35.23 \%)$ and $40(100 \%)$ breast cancer and breast fibroadenoma cases, respectively. There was a significantly lower level of RUNX 3 expression in the cancers than in the benign tumors $(\mathrm{p}<0.01)$. The representative pictures are shown in figure 2 . To further confirm these observations, RT-PCR and Western blot assay were performed using 30 pairs of breast cancer and their matching normal breast tissues.

Western blot analysis disclosed that the RUNX3 protein of $44 \mathrm{kDa}$ was detected in 15 of 30 (50\%) breast cancers, but was detected in all normal breast tissues. RTPCR was performed as well. Of the 30 cancer tissues, 16 (53.33\%) expressed RUNX3 mRNA. Only 1 case that expressed RUNX3 mRNA did not express RUNX3 protein, as shown by Western blot analysis. On the other hand, all normal breast tissues expressed RUNX3 mRNA. The results of the RT-PCR and the Western blot analysis were consistent with those of the immunohistochemistry analysis. These results showed that RUNX3 was commonly expressed in normal human breast tissues and benign breast tumors, but decreased or absent in breast cancers.

By immunohistochemistry analysis, we also found that the RUNX3-positive staining of all breast fibroadenomas and normal breast ducts adjacent to the cancers in the cancer tissues was located at nuclear regions. We found 4 types of staining patterns for RUNX3 in breast cancer tissues: (1) negative in both the nucleus and the cytoplasm (negative, 49 cases), (2) positive in the nucleus and negative in the cytoplasm (positive, 28 cases), (3) positive in the nucleus and the cytoplasm (positive, 3 cases) and (4) positive in the cytoplasm and negative in the nucleus (negative, 8 cases). There was no different staining pattern between invasive components and noninvasive components in the 11 cancer tissues with RUNX3 protein cytoplasm staining.

\section{Frequent Hypermethylation of the RUNX3 Gene in}

Breast Cancer

To investigate whether the gene silencing was because of hypermethylation of RUNX3, MSP was performed in 5 breast cancer cell lines, the normal breast cell line Hs578Bst and 30 primary breast cancer tissues and corresponding normal tissues. We found that 2 kinds of cells (T47D and MCF7) exhibited CpG island methylation in the RUNX3 promoter (fig. 3).

In tumor tissues, methylation was detected in 13 of the 15 tissues (86.67\%) that did not express RUNX3 protein, but was never detected in any surrounding normal tissues. In normal tissue samples, unmethylated DNA was

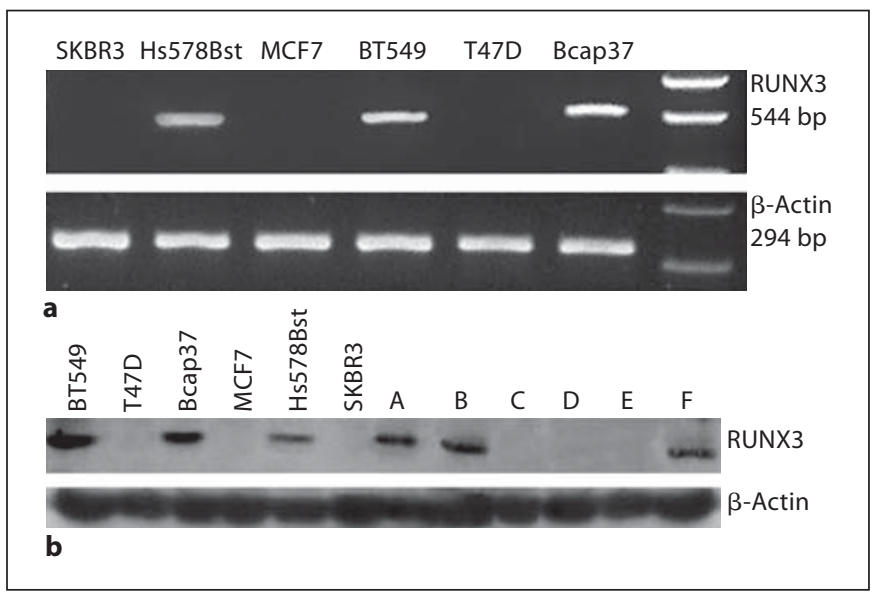

Fig. 1. a RT-PCR analysis of RUNX3 gene expression in 5 human breast cancer cell lines and a normal breast cell line (Hs578Bst). The loss of RUNX3 mRNA expression was found in 3 of 5 cancer cell lines (SKBR3, MCF7 and T47D), but not in the other cell lines (BT549, Bcap37 and Hs578Bst). $\beta$-Actin was amplified by RTPCR as an internal control. b Western blot analysis of RUNX3 expression not only in human breast cancer cell lines, but also in human breast cancer and their matching normal breast tissues. RUNX3 protein expression was noted in BT549, Bcap37 and Hs578Bst. A, B and F were normal breast tissues in which RUNX3 protein was clearly expressed. C, D and E were their matching cancer tissues that did not express RUNX3 protein. $\beta$-Actin acted as an internal control.

amplified in all 30 samples. Of 9 stage III cases, 7 (77.78\%) showed RUNX3 methylation. For stage I and II cases, 2 of $9(22.22 \%)$ and 4 of $12(33.33 \%)$ exhibited RUNX3 methylation, respectively. Of 13 RUNX3-methylated cases, 9 (69.23\%) were with lymph node metastasis. These results indicate that RUNX3 is silenced in approximately $43.33 \%$ (13/30) of breast cancers due to hypermethylation in the promoter region, and RUNX3 methylation was detected mostly in advanced-stage (III) cancer specimens.

\section{The Correlation between RUNX3 Expression and Clinicopathological Parameters}

We examined the relationship between RUNX3 expression and clinicopathological features in 88 breast cancer samples by immunohistochemistry. RUNX3 expression was not associated with age, tumor types and pathological grade, but it was associated with clinical stage and lymph node metastasis. The expression of RUNX3 protein was higher in the early-stage cases than in the advancedstage breast cancer cases. The expression of RUNX3 protein was lower in the presence of lymph node metastasis cases than in their absence. In addition, the expression of 


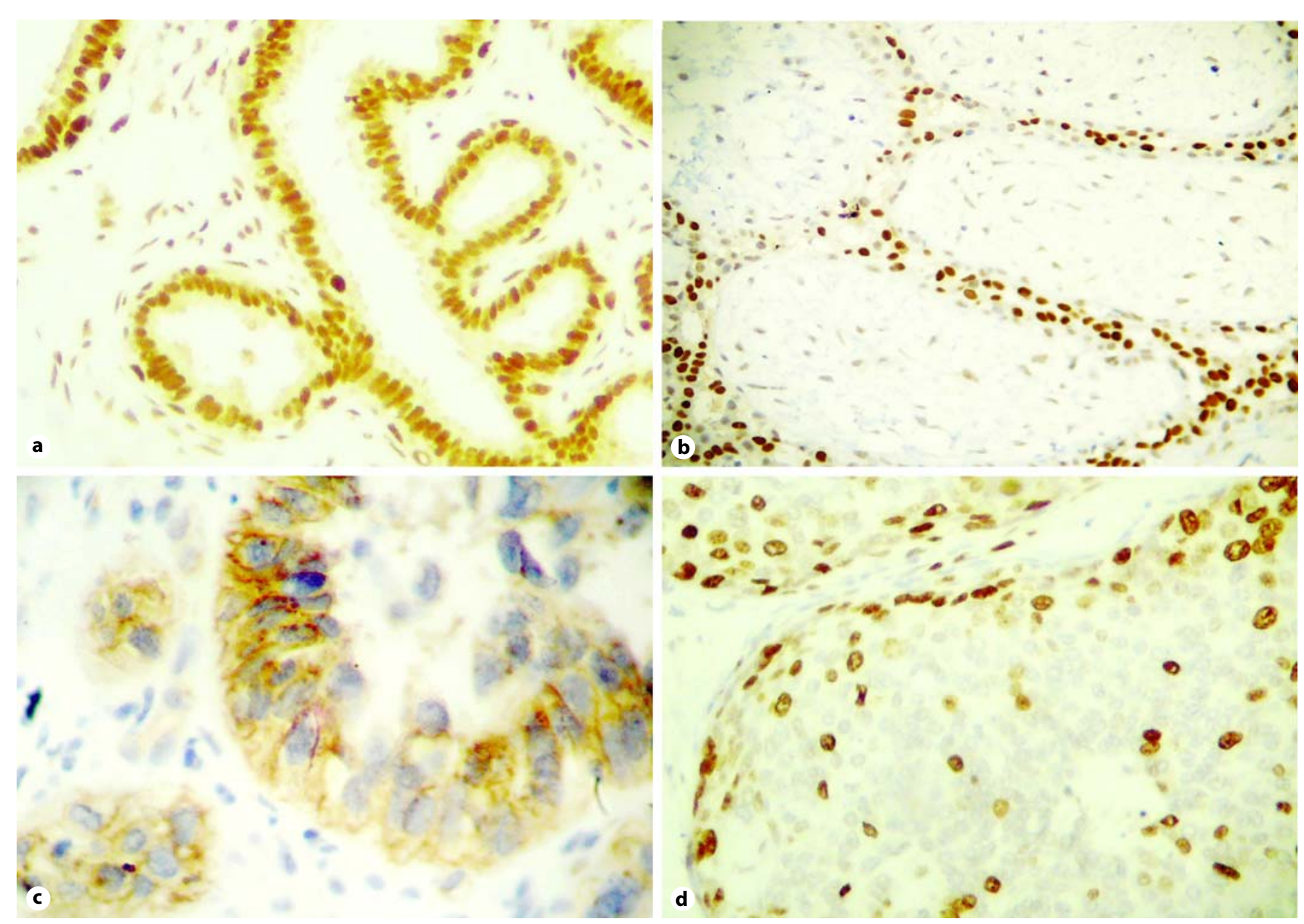

Fig. 2. Immunohistochemical analysis of RUNX3 expression using a rabbit polyclonal antibody against human RUNX3. RUNX3 expression is detected in the nucleus in the normal breast tissue adjacent to the cancer (a) and breast fibroadenoma tissue (b). c The positive expression of RUNX3 in ductal carcinoma in situ tissue was stained in part of nuclei. $\mathbf{d}$ RUNX3 expression in invasive ductal carcinoma was not nuclear but cytoplasmic staining.

Fig. 3. Methylation analysis of RUNX3 gene in 5 human breast cancer cell lines and Hs578Bst. The promoter region of RUNX3 gene was methylated in 2 cancer cell lines (MCF7 and T47D). A and B were unmethylated and methylated PCR controls of the RUNX3 gene, respectively. $\mathrm{M}=$ Methylation products; $\mathrm{U}=$ unmethylation products.

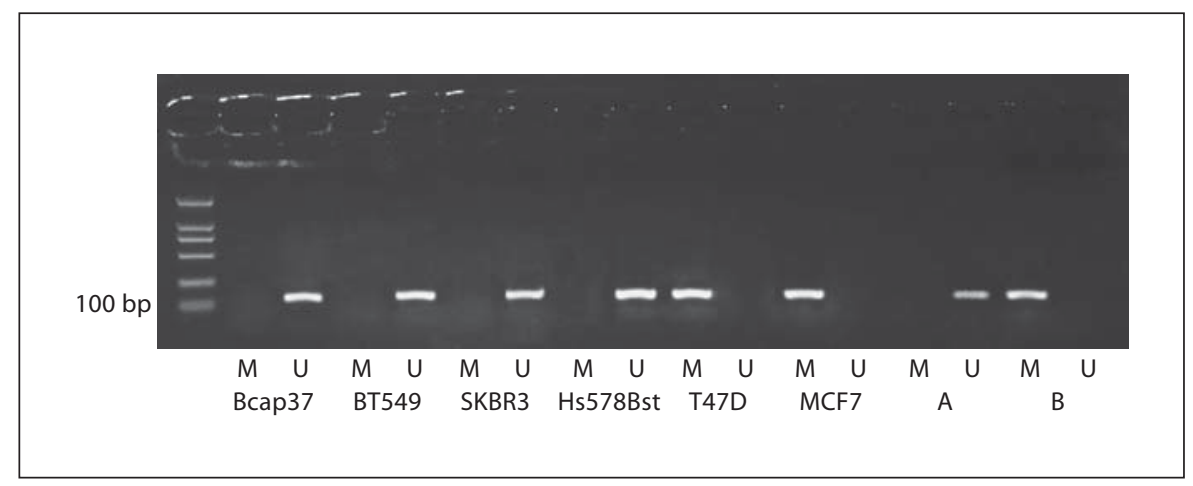


RUNX3 protein was higher in ER- and PR-positive cases than in ER- and PR-negative cases (table 1).

\section{Survival Analysis of Breast Cancer Patients}

Kaplan-Meier survival curves showed that the 5-year survival rate was $83.87 \%$ in the 31 patients with positive RUNX3 expression and $54.39 \%$ in the 57 patients with negative RUNX3 expression, the value being significantly different ( $\mathrm{p}<0.005$; fig. 4$)$. In a Cox proportional hazards model for multivariate analysis, the reduced RUNX3 expression was an independent predictor of inferior survival after we adjusted the effect of the covariates including the patients' RUNX3 expression level, lymph node status, ER and PR status, histopathological grade, age and sex. The odds ratio in the group with negative $(3.017,95 \%$ confidence interval 1.136-16.325) RUNX3 expression was significantly higher than that in the group with positive RUNX3 expression.

\section{Discussion}

The RUNX3 gene is located on human chromosome $1 \mathrm{p} 36$, a region that has long been suspected to harbor one or more suppressors of various tumors [8, 12-13]. Recent studies suggested that RUNX3 has been implicated as a tumor suppressor in several tumors, including gastric cancer, colorectal cancer, hepatocellular cancer and esophageal squamous cell carcinoma among others $[6$, 14-16]. The effect of RUNX3 on breast cancer has not been clearly studied. In this study, we have demonstrated that the expression of RUNX3 decreased in breast cancer tissues and breast cancer cell lines, whether analyzed by Western blot, RT-PCR or immunohistochemistry. This indicated that inactivation of RUNX3 may play an important role in tumorigenesis of breast carcinomas.

Although the importance of genetic mutation in carcinogenesis has long been recognized, DNA methylation has also been a powerful mechanism for suppression of gene activity [17-19]. More and more studies have revealed that hypermethylation of the $\mathrm{CpG}$ island in the promoter region is an alternative way to silence some cancer-associated genes. To date, many genes, such as RB, p16, E-cadherin, HIN-1 and RASSF1A, have been shown to be inactivated by hypermethylation in various tumors [20-24]. Li et al. [6] reported that RUNX3 is frequently inactivated in gastric cancer cell lines by hypermethylation of $\mathrm{CpG}$ islands in the exon 1 region. Therefore, RUNX3 seems to be a new tumor suppressor gene that is silenced by promoter hypermethylation in cancer cells.

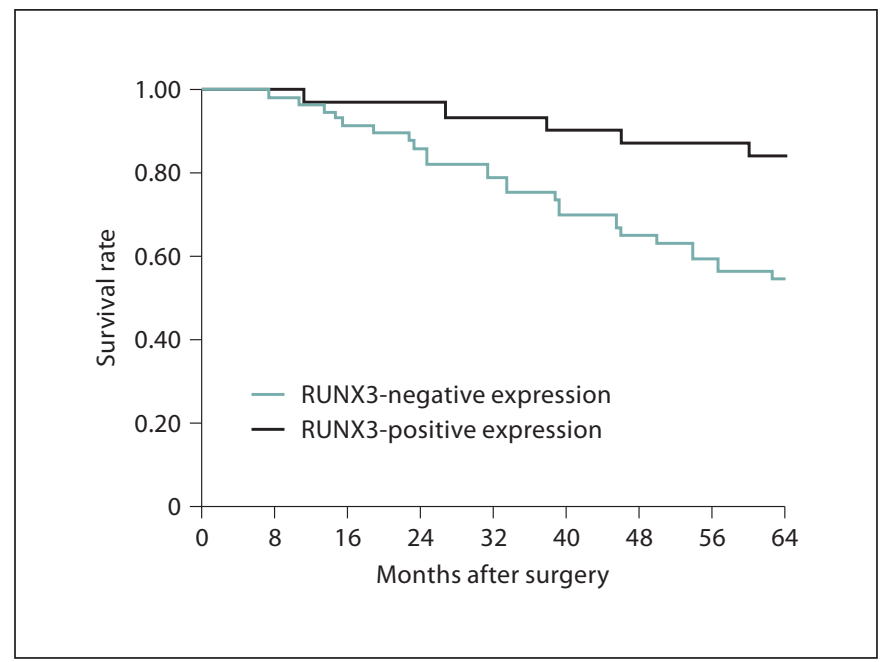

Fig. 4. Kaplan-Meier survival curves for overall survival. The 5 -year survival rate was $83.87 \%$ in 31 patients with positive expression of RUNX3 and $54.39 \%$ in 57 patients with negative expression, the value being significantly different $(\mathrm{p}<0.005)$.

In the present study, we found that hypermethylation of the RUNX3 promoter region occurred in 13 of 30 (43.33\%) breast cancer tissues and 2 (T47D and MCF7) of 5 breast cancer cell lines (40\%) by using MSP. In addition, we found the 2 cancer cell lines that had hypermethylation in the $\mathrm{CpG}$ island of the RUNX3 promoter region did not express RUNX3 mRNA or protein, whereas high expression was observed in the cancer cell lines (Bcap37 and BT549) with no methylation of the same region. This result indicates that the methylation status of the RUNX3 promoter region correlates inversely with the expression of RUNX3. But SKBR3, where RUNX3 mRNA and protein were negative expressed, did not exhibit CpG island methylation in the RUNX3 promoter. This was in accordance with the findings of Lau et al. [25]. This suggests that other mechanisms may be involved in the regulation of RUNX3 expression.

In cancer tissues, methylation status of the RUNX3 promoter region correlates inversely with the expression of RUNX3, too. According to our statistical analysis of clinicopathological data, hypermethylation of the RUNX3 promoter region was found to be significantly higher in the advanced stage in breast cancer. These results indicate that hypermethylation of the RUNX3 promoter region is associated with the loss of RUNX3 protein expression. RUNX3 acts as a possible potent tumor suppressor gene in breast cancers, as well as in gastric cancers. 
Immunohistochemistry results revealed that the positive rate of RUNX3 expression in breast cancers was much lower than that in benign breast tumors. The decrease in RUNX3 expression was inversely correlated with clinical stage and lymph metastasis. Interestingly, it was observed that the expression of RUNX3 protein was increased in the ER- and PR-positive cases. The mechanism is not clear and needs to be further studied. Lower levels of RUNX3 in human breast cancer are significantly associated with a worse patient survival. RUNX3 was an independent predictor of poor patient outcome.

Ito et al. [26] reported that RUNX3 expression mislocalized from the nucleus to the cytoplasm in gastric cancer. Lau et al. [25] yielded a similar result in breast cancer [25]. In the present study, we also examined the protein localization of RUNX3. We observed cytoplasmic localization of RUNX3 in 11 cases of breast cancers. However, nuclear expression of RUNX3 is very strong in all breast fibroadenomas and normal breast ducts found in the cancer tissues. In many signaling pathways, the nuclear import of transcription factors is an essential element. Transcription factors localized in the cytoplasm are thought to be in a basal, inactive state. RUNX3 localized in the cytoplasm cannot act as a transcription factor and does not elicit tumor-suppressive effects [26]. Cytoplasmic retention of RUNX3 may result from the absence of down- regulation of one or more components of a signaling pathway required for RUNX3 nuclear translocation. The importance of the nuclear localization of RUNX3 is clear, but the mechanisms need further study.

In summary, our findings demonstrate 2 points about the relationship between RUNX3 and breast cancer. First, RUNX3 expression in breast cancer is very low both at mRNA and protein level. A poor prognosis in breast cancer is associated with a lower expression of RUNX3. Second, methylation of the RUNX3 promoter region occurs commonly both in cell lines and in primary breast cancers. The aberrant methylation of RUNX3 is tumor specific, since it was not observed in normal breast tissues and breast normal cell line. Methylation is correlated with the silencing of RUNX3 expression. These results suggest that the loss of RUNX3 expression caused by hypermethylation is frequently associated with the evolution of breast cancer. RUNX3 may be a candidate for prognosis and molecular target therapy.

\section{Acknowledgement}

This work was supported in part by a Grant-in-Aid for Scientific Research from the Department of Education of Heilongjiang (grant No. 11521080).

\section{References}

1 Hanai J, Chen LF, Kanno T, Ohtani-Fujita N, Kim WY, Guo WH, Imamura T, Ishidou Y, Fukuchi M, Shi MJ, Stavnezer J, Kawabata $\mathrm{M}$, Miyazono K, Ito Y: Interaction and functional cooperation of $\mathrm{PEBP} 2 / \mathrm{CBF}$ with Smads: synergistic induction of the immunoglobulin germline $\mathrm{C} \alpha$ promoter. J Biol Chem 1999;274:31577-31582.

- 2 Okuda T, van Dursen J, Hiebert SW, Grosveld G, Downing JR: AML1, the target of multiple chromosomal translocation in human leukemia, is essential for normal fetal liver hematopoiesis. Cell 1996;84:321-330.

-3 Look AT: Oncogenic transcription factors in the human acute leukemias. Science 1997; 278:1059-1064.

-4 Lee B, Thirunavukkarasu K, Zhou L, Pastore L, Baldini A, Hecht J, Geoffroy V, Ducy P, Karsenty G: Missense mutations abolishing DNA binding of the osteoblastspecific transcription factor OSF2/CBFA1 in cleidocranial dysplasia. Nat Genet 1997;16:307-310.

5 Weinstein M, Yang X, Deng C: Functions of mammalian Smad genes as revealed by targeted gene disruption in mice. Cytokine Growth Factor Rev 2000;11:49-58.
-6 Li QL, Ito K, Sakakura C, Fukamachi H, Inoue K, Chi XZ, Lee KY, Nomura S, Lee CW, Han SB, Kim HM, Kim WJ, Yamamoto H, Yamashita N, Yano T, Ikeda T, Itohara S, Inazawa J, Abe T, Hagiwara A, Yamagishi H, Ooe A, Kaneda A, Sugimura T, Ushijima $\mathrm{T}$, Bae SC, Ito Y: Causal relationship between the loss of RUNX3 expression and gastric cancer. Cell 2002;109:113-124.

-7 Bae SC, Ogawa E, Maruyama M, Oka H, Satake M, Shigesada K, Jenkins NA, Gilbert DI, Copeland NG, Ito Y: PEBP2aB/mouse AML1 consists of multiple isoforms that possess differential transactivation potentials. Mol Cell Biol 1994;14:3242-3252.

-8 Schwab M, Praml C, Amler LC: Genomic instability in $1 \mathrm{p}$ and human malignancies. Genes Chromosomes Cancer 1996;16:211229.

-9 Suzuki M, Toyooka S, Miyajima K, Iizasa T, Fujisawa T, Bekele NB, Gazdar AF: Alterations in the mitochondrial displacement loop in lung cancers. Clin Cancer Res 2003; 9:5636-5641.
10 Herman JG, Graff JR, Myohanen S, Nelkin BD, Baylin SB: Methylation-specific PCR: a novel PCR assay for methylation status of CpG islands. Proc Natl Acad Sci USA 1996; 93:9821-9826.

11 Wang L, Wei D, Huang S, Peng Z, Le X, Wu TT, Yao J, Ajani J, Xie K: Transcription factor Spl expression is a significant predictor of survival in human gastric cancer. Clin Cancer Res 2003;9:6371-6380.

12 Weith A, Brodeur GM, Bruns GA, Matise TC, Mischke D, Nizetic D, Seldin MF, van Roy N, Vance J: Report of the second international workshop on human chromosome 1 mapping 1995. Cytogenet Cell Genet 1996; 72:114-144

13 Fang W, Piao Z, Buyse IM, Simon D, Sheu JC, Perucho M, Huang S: Preferential loss of a polymorphic RIZ allele in human hepatocellular carcinoma. Br J Cancer 2001;84:743747.

$14 \mathrm{Ku} J \mathrm{~L}$, Kang SB, Shin YK, Kang HC, Hong SH, Kim IJ, Shin JH, Han IO, Park JG: Promoter hypermethylation downregulates RUNX3 gene expression in colorectal cancer cell lines. Oncogene 2004;23:6736-6742. 
15 Xiao WH, Liu WW: Hemizygous deletion and hypermethylation of RUNX3 gene in hepatocellular carcinoma. World J Gastroen terol 2004; 10:376-380.

-16 Hiramatsu T, Osaki M, Ito Y, Tanji Y, Tokuyasu N, Ito H: Expression of RUNX3 protein in human esophageal mucosa and squamous cell carcinoma. Pathobiology 2005;72:316-324.

17 Baylin SB, Herman JG: DNA hypermethylation in tumorigenesis: epigenetics joins genetics. Trends Genet 2000;16:168-174.

- 18 Eng C, Herman JG, Baylin SB: A bird's eye view of global methylation. Nat Genet 2000; 24:101-102.

-19 Lee S, Kim WH, Jung HY, Yang MH, Kang $\mathrm{GH}$ : Aberrant $\mathrm{CpG}$ island methylation of multiple genes in intrahepatic cholangiocarcinoma. Am J Pathol 2002;161:1015-1022.
20 Jones PA, Laird PW: Cancer epigenetics comes of age. Nat Genet 1999;21:163-167.

-21 Tada Y, Wada M, Taguchi K, Mochida Y, Kinugawa N, Tsuneyoshi M, Naito S, Kuwano M: The association of death-associated protein kinase hypermethylation with early recurrence in superficial bladder cancers. Cancer Res 2002;62:4048-4053.

-22 Chan MW, Chan LW, Tang NL, Lo KW, Tong JH, Chan AW, Cheung HY, Wong WS, Chan PS, Lai FM, To KF: Frequent hypermethylation of promoter region of RASSF1A in tumor tissues and voided urine of urinary bladder cancer patients. Int J Cancer 2003; 104:611-616.

$23 \mathrm{Ku}$ JL, Yoon KA, Kim IJ, Kim WH, Jang JY, Suh KS, Kim SW, Park YH, Hwang JH, Yoon YB, Park JG: Establishment and characterisation of six human biliary tract cancer cell lines. Br J Cancer 2002;87:187-193.
24 Yang Q, Kieman CM, Tian Y, Salwen HR, Chlenski A, Brumback BA, London WB, Cohn SL: Methylation of CASP8, DCR2, and HIN-1 in neuroblastoma is associated with poor outcome. Clin Cancer Res 2007;13: 3191-3197.

25 Lau QC, Raja E, Salto-Tellez M, Liu Q, Ito K, Inoue M, Putti TC, Loh M, Ko TK, Huang C, Bhalla KN, Zhu T, Ito Y, Sukumar S: RUNX3 is frequently inactivated by dual mechanisms of protein mislocalization and promoter hypermethylation in breast cancer. Cancer Res 2006;66:6512-6520.

26 Ito K, Liu Q, Salto-Tellez M, Yano T, Tada K, Ida $\mathrm{H}$, Huang $\mathrm{C}$, Shah $\mathrm{N}$, Inoue M, Rajnakova A, Hiong KC, Peh BK, Han HC, Ito T, Teh M, Yeoh KG, Ito Y: RUNX3, a novel tumor suppressor, is frequently inactivated in gastric cancer by protein mislocalization. Cancer Res 2005;65:7743-7750. 